\title{
Research on Logistics Demand Forecast in Southeast Asia
}

\section{Thi Yen Nguyen}

Faculty of Transport Safety and Environment, University of Transport and Communications, Ha Noi, Vietnam

Email: nguyenyenutc2009@gmail.com

How to cite this paper: Nguyen, T.Y. (2020) Research on Logistics Demand Forecast in Southeast Asia. World Journal of Engineering and Technology, 8, 249-256. https://doi.org/10.4236/wjet.2020.83020

Received: June 13, 2020

Accepted: July 7, 2020

Published: July 10, 2020

Copyright $\odot 2020$ by author(s) and Scientific Research Publishing Inc. This work is licensed under the Creative Commons Attribution International License (CC BY 4.0).

http://creativecommons.org/licenses/by/4.0/

\begin{abstract}
This article predicts Southeast Asia's logistics needs from a Southeast Asian logistics development perspective. This is not only an important prerequisite for supporting Southeast Asia's trade policy, but also promoting the development of Southeast Asia's logistics industry, building logistics infrastructure and improving the level of logistics services. Due to differences in economic development levels, trade structures, infrastructure construction and logistics development levels of Southeast Asian countries. Therefore, considering the actual situation of Southeast Asian countries, this article selected 21 cities in Southeast Asia as the research object. Use L-OD logistics demand forecasting method to forecast logistics demand in Southeast Asia. Obtain the amount of logistics occurrence and attraction in 21 cities in Southeast Asia in the future. And construct a double constrained gravity model to predict logistics distribution in Southeast Asia. The forecast results provide scientific data support for future logistics development planning in Southeast Asia.
\end{abstract}

\section{Keywords}

Southeast Asian, Logistics, Demand Forecast, Double Constrained Gravity Model

\section{Introduction}

Following the regional integration of Southeast Asian, the international trade in the Southeast Asian region continues strengthening, and the Southeast Asian gradually becomes the fastest-growing region for exchange of goods. The rapid economic development and the rapid growth of trade have created a huge demand for the Southeast Asian regional logistics industry. Promote the rapid development of transportation, warehousing, distribution, loading and unloading, postal, telecommunications and other industries related to the logistics industry. 
At present, the economic and logistics development levels of various cities in Southeast Asia are uneven, and there are great differences. Therefore, how to apply effective logistics forecasting methods has very important practical significance for the logistics development needs of various cities in Southeast Asia. For the forecast methods of logistics are a very rich field of research scholars. For many logistics demand forecasting methods, analyze from the macro and micro levels. At the macro level, some scholars analyzed the relationship between logistics demand and supply for research. From a micro level, Zhang Jin [1] proposed a streamlined network of demand and supply to build a suitability. Silva [2] uses nonparametric time series and singularity, forecasting technology to forecast freight volume and the prediction model of the economic recession. Wang [3] studied the utilization rate and application scope of different forecasting methods. Yu [4] forecasts the logistics needs of Yunnan Province. Set strategic goals for logistics companies in Yunnan Province to reduce costs and improve logistics efficiency. Tian [5] used the L-OD method to forecast logistics demand of Luzhou. However, at present, scholars have deepened the logistics network from the perspective of logistics demand development and logistics demand characteristics. There are few studies, and there are few studies in Southeast Asia. Based on the geographical location, economy, trade and logistics of cities in Southeast Asian countries. The 21 cities in Southeast Asia were selected as the research subjects which are the most economically developed and logistics developed in Southeast Asia. Mainly include: Singapore; Kuala Lumpur, Selangor, Perak, Johor, Pahang, Sarawak of Malaysia; Bangkok and Chonburi of Thailand; Jakarta, Java, Riau, South Kalimantan and East Kalimantan of Indonesia; Ha Noi, Da Nang and Ho Chi Minh of Viet Nam; Manila of Philippines; Vientiane of Laos; Phnom Penh of Cambodia and Yangon of Myanmar. Using the L-OD stage method for logistics demand forecasting. It predicts the occurrence of logistics in 21 cities in Southeast Asia, the distribution of attracted logistics and the direction of logistics. It provides theoretical basis and practical application value for the development of logistics in the Southeast Asia region, logistics planning, and the optimization of the logistics network.

\section{Southeast Asia Regional Logistics Forecast}

\subsection{Logistics Area Division}

Based on L-OD logistics demand forecasting, analysis of the total logistics in Southeast Asia, and includes various forecasting methods and models. The basic principle of the four-stage forecasting method is to first investigate the regional economy, the level of logistics development, and the logistics L-OD survey among the areas, etc. Then build a generative model according to the regional economic growth trend, and get the future regional logistics demand, namely logistics generation forecast, logistics distribution forecast, logistics network allocation, etc. This article considers the administrative divisions of Southeast Asian countries, the economic development of various countries, and the scope of rad- 
iation to other regions, taking 21 cities in Southeast Asia as the research object. Singapore is area 1. Malaysia's Kuala Lumpur, Selangor, Perak, Johor, Pahang, Sarawak are areas 2, 3, 4, 5, 6, 7. Thailand's Bangkok and Chon Buri are areas 8 and 9. Indonesia's Jakarta, Java, Riau, South Kalimantan and East Kalimantan are areas 10,11, 12, 13, 14. Vietnam's Hanoi, Da Nang, and Ho Chi Minh are areas 15, 16, and 17. Philippines's Manila is area 18. Myanmar's Yangon is area 19. Cambodia's Phnom Penh is area 20. Lao's Vientiane is area 21.

\subsection{Key Model of L-OD Prediction Method}

1) Elastic coefficient method

In this paper, the elastic coefficient method is used to predict the material flow. Considering that the growth of total logistics volume is related to GDP, the elasticity coefficient is set as the ratio of the growth rate of total logistics volume to the growth rate of GDP. The specific model is shown below.

$$
\begin{gathered}
\alpha^{k}=\eta^{\mathrm{k}} / \gamma^{k}, k=1,2, \cdots, 21 . \\
L_{t}^{k}=L_{0}^{k}\left(1+\eta^{k}\right)^{\Delta t}, k=1,2, \cdots, 21 . \\
P_{t}^{k}=a_{t}^{k} \cdot L_{t}^{k}, k=1,2, \cdots, 21 . \\
A_{t}^{k}=b_{t}^{k} \cdot L_{t}^{k}, k=1,2, \cdots, 21 .
\end{gathered}
$$

In the formula: $\alpha^{k}$ : the elasticity coefficient of the kth logistics area;

$\eta^{k}$ : the growth rate of the total logistics volume of the kth logistics community;

$\gamma^{k}$ : GDP growth rate of the kth logistics community;

$L_{t}^{k}$ : the total logistics volume of the kth logistics community in year $t$;

$L_{0}^{k}$ : he predicted total logistics volume of the kth logistics district in the base year;

$\Delta t:$ predicted years;

$a_{t}^{k}$ : the weight of logistics occurrence in the kth logistics community in year $t$,

$A_{t}^{k}$ : the logistics attraction of the kth logistics community in year $t$,

$b_{t}^{k}$ : the weight of logistics attraction of the kth logistics community in year $t$.

2) Double constrained gravity model

In this paper, the dual-constrained gravity model method is used to predict logistics distribution. This method can better reflect the logistics distribution of the community and its social relationship with the economy, land use, and comprehensive transportation. The model is:

$$
d_{i j}=k \frac{F_{i} X_{j}}{R_{i j}}
$$

The dual-constrained gravity model satisfies:

$$
\sum_{i} D_{i j}=X_{j}, \sum_{i} D_{i j}=F_{i}
$$

The two constraints, the basic form is:

$$
D_{i j}=A_{i} B_{j} X_{j} F_{i} R_{i j}
$$




$$
\begin{aligned}
A_{i} & =\left[\sum_{j} B_{j} F_{i} R_{i j}\right]^{-1} \\
B_{j} & =\left[\sum_{i} A_{i} X_{i} R_{i j}\right]^{-1}
\end{aligned}
$$

The logistics distribution prediction is expressed by the impedance distance:

$$
R_{i j}=k_{i j}^{-\alpha}
$$

In the formula: $D_{i j}$ is the distribution of logistics from area $i$ to area $j$

$F_{i}$ is the volume of logistics generated in area $i$;

$X_{j}$ is the logistics attraction of area $j$

$D_{i j}$ is the logistics impedance of area $i$ to area $j$;

$A_{i}, B_{j}$ is the fitting coefficient;

$k_{i j}$ is the distance from area $i$ to area $j$;

$\alpha$ is the undetermined coefficient.

\subsection{Logistics Forecast Results}

1) Forecast of Southeast Asia Logistics Volume

Southeast Asia's future logistics forecast is the region's cargo volume forecast. According to the statistics of different countries, the volume index is chosen to represent the logistics development of Southeast Asia countries. Use the elasticity coefficient method to predict the volume of goods in the Southeast Asia region. Through the statistical yearbook and statistical bulletin data of Southeast Asian countries, the logistics occurrence and attraction among Southeast Asian cities (Table 1).

Then the elasticity coefficient method is used to predict the logistics occurrence and attraction of 21 cities in Southeast Asia (Table 2).

In 2025, the occurrence and attraction of logistics in 21 districts in Southeast Asia are shown in Figure 1.

Use the double constrained gravity model to obtain the logistics distribution forecast lines of 21 regions in Southeast Asia in 2025, as shown in Figure 2.

As can be seen from Figure 1, the logistics attraction and occurrence of 21 areas in Southeast Asia are basically the same. Among them, Singapore (area 1) and Thailand (areas 8 and 9) have a relatively large amount of logistics occurrence and attraction, while Myanmar (area 19) and Laos (area 21) have a relatively small amount of logistics occurrence and attraction.

From the analysis of the distribution prediction results in 2025 , we can conclude that:

- For the ASEAN region, the distribution of logistics is mainly concentrated in area 1 of Singapore, area 2 and area 3 of Malaysia, area 8 of Thailand, area 10 of Indonesia, area 17 of Vietnam.

- Thailand (area 8 and 9) and Cambodia (area 20) have relatively large exchange volumes. Singapore (area 1) and the Philippines (area 18) have relatively large exchange volumes. 


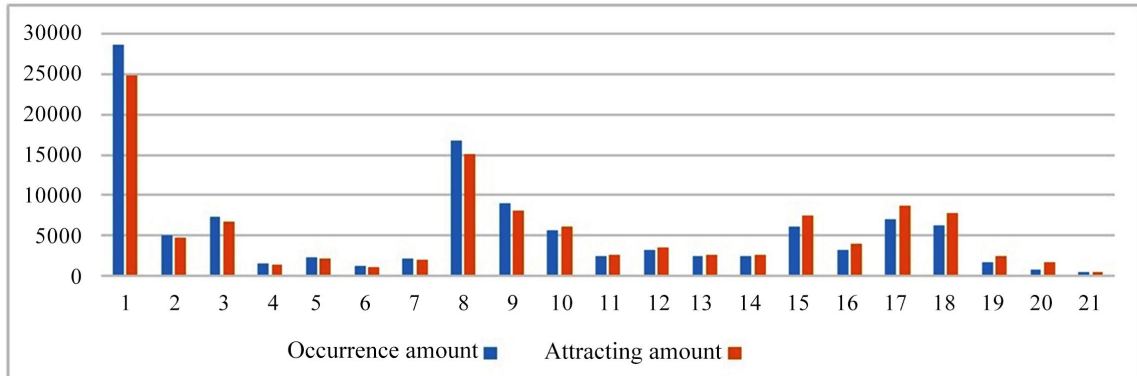

Figure 1. 2025 Logistics occurrence and attraction in 21 areas in Southeast Asia $(100,000$ tons).

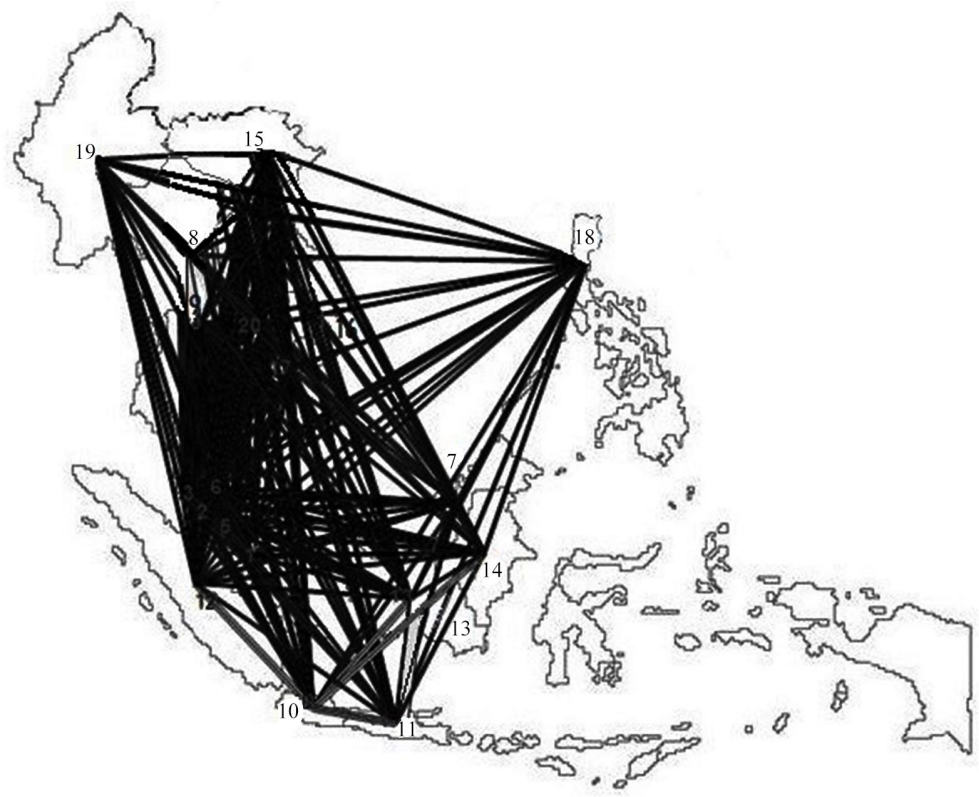

Figure 2. Expected line graph of material flow distribution in 2025.

Table 1. 2015 Logistics occurrence and attraction of Southeast Asian (Unit: 100,000 tons).

\begin{tabular}{cccccc}
\hline $\begin{array}{c}\text { Area } \\
\text { number }\end{array}$ & $\begin{array}{c}\text { Occurrence } \\
\text { amount }\end{array}$ & $\begin{array}{c}\text { Attracting } \\
\text { amount }\end{array}$ & $\begin{array}{c}\text { Area } \\
\text { number }\end{array}$ & $\begin{array}{c}\text { Occurrence } \\
\text { amount }\end{array}$ & $\begin{array}{c}\text { Attracting } \\
\text { amount }\end{array}$ \\
\hline 1 & 20251 & 17,590 & 12 & 1809.6 & 1947.6 \\
2 & 3275.7 & 3012.6 & 13 & 1358 & 1462 \\
3 & 4712 & 4333.5 & 14 & 1356.4 & 1459.4 \\
4 & 957.5 & 880.6 & 15 & 3375 & 4170 \\
5 & 1499.3 & 1378.9 & 16 & 1824 & 2254 \\
6 & 781.1 & 718.3 & 17 & 3923 & 4846 \\
7 & 1373.3 & 1263 & 18 & 3861 & 4745 \\
8 & 8121.7 & 7347.6 & 19 & 1012 & 1549 \\
9 & 4373.3 & 3956.4 & 20 & 2401 & 859 \\
10 & 3166.8 & 3408.3 & 21 & 352 & 280 \\
11 & 1357.2 & 1460.7 & & & \\
\hline
\end{tabular}


Table 2. 2025 Logistics occurrence and attraction of Southeast Asian (Unit: 100,000 tons).

\begin{tabular}{cccccc}
\hline $\begin{array}{c}\text { Area } \\
\text { number }\end{array}$ & $\begin{array}{c}\text { Occurrence } \\
\text { amount }\end{array}$ & $\begin{array}{c}\text { Attracting } \\
\text { amount }\end{array}$ & $\begin{array}{c}\text { Area } \\
\text { number }\end{array}$ & $\begin{array}{c}\text { Occurrence } \\
\text { amount }\end{array}$ & $\begin{array}{c}\text { Attracting } \\
\text { amount }\end{array}$ \\
\hline 1 & 28,562 & 24,810 & 12 & 3239 & 3487 \\
2 & 5087 & 4678 & 13 & 2431 & 2618 \\
3 & 7317 & 6729 & 14 & 2427 & 2613 \\
4 & 1487 & 1368 & 15 & 6042 & 7465 \\
5 & 2329 & 2141 & 16 & 3265 & 4034 \\
6 & 1213 & 1116 & 17 & 7022 & 8675 \\
7 & 2133 & 1961 & 18 & 6286 & 7726 \\
8 & 16,722 & 15,129 & 19 & 1647 & 2522 \\
9 & 9005 & 8146 & 20 & 4721 & 1689 \\
10 & 5669 & 6101 & 21 & 546 & 434 \\
11 & 2430 & 2615 & & & \\
\hline
\end{tabular}

- The occurrence and attraction of Singapore (area 1) accounted for more than the rest of the Southeast Asian region. It shows that Singapore is the regional logistics hub of Southeast Asian, which concentrates the main part of Southeast Asian regional logistics exchange volume. Selangor in Malaysia (area 3), Bangkok in Thailand (area 8), Ho Chi Minh in Vietnam (area 17), and Jakarta in Indonesia (area 10) are the second largest in terms of occurrence and attraction, with a rapid growth rate.

\section{Southeast Asia Regional Logistics Network Traffic Distribution}

Through the logistics forecast results of various regions in Southeast Asia. It can be seen that the flow of freight in Southeast Asia. Among the 21 cities in Southeast Asia, Singapore is the logistics hub, radiating the cities in the entire Southeast Asian region. On the Southeast Asian Peninsula, Thailand is the main center of radiation to Vietnam (Hanoi), Philippines (Manila), Myanmar (Yangon), Cambodia Phnom Penh) and Laos (Vientiane). Southeast Asia peninsula mainly radiates Malaysia (Sarawak) and Indonesia (Jakarta, Java, South Kalimantan, East Kalimantan, Riau) centered on Singapore and Indonesia (Table 3).

At present, the logistics infrastructure of countries in Southeast Asia is unbalanced. The cargo transportation mode is unreasonable, and the main cargo transportation is concentrated on water transportation. And the unbalanced freight volume between Southeast Asia. Therefore, corresponding countermeasures and suggestions are proposed for the Southeast Asian logistics network. While Southeast Asian countries continue to strengthen domestic infrastructure construction, they should also increase cooperation among countries, infrastructure interconnection construction. Southeast Asian countries including 
Table 3. Logistics exchange volume between Southeast Asia.

\begin{tabular}{ll}
\hline ASEAN region & Major countries in logistics exchange volume \\
\hline Singapore & Malaysia (Selangor, Kuala Lumpur) $>$ Indonesia (Jakarta) $>$ Thailand (Bangkok) \\
Malaysia & Thailand (Bangkok, Chonburi) $>$ Indonesia (Jakarta) \\
Thailand & $\begin{array}{l}\text { Singapore }>\text { Malaysia (Selangor, Kuala Lumpur) }>\text { Vietnam (Ho Chi Minh, } \\
\text { Hanoi) }\end{array}$ \\
Indonesia & Singapore $>$ Philippines \\
Vietnam & Singapore $>$ Thailand (Bangkok) $>$ Laos (Vientiane) \\
Philippines & Singapore $>$ Thailand (Bangkok) \\
Myanmar & Singapore $>$ Thailand (Bangkok) \\
Cambodia & Thailand (Bangkok) $>$ Vietnam (Ho Chi Minh) \\
Laos & Thailand $>$ Vietnam (Hanoi) \\
\hline
\end{tabular}

Vietnam, Indonesia, the Philippines, Myanmar, Cambodia, and Laos have weak and backward railway networks. It is necessary to strengthen the construction of the railway network, and at the same time improve the highway network and improve the quality of highway grades.

\section{Conclusions}

This article focuses on Southeast Asia's economic, trade and logistics analysis to study Southeast Asia's logistics demand. Using the L-OD logistics demand forecasting method.

Southeast Asia is divided into 21 communities then the logistics occurrence, attraction and logistics exchange volume of Southeast Asian countries are predicted. The prediction results show that compared with other Southeast Asian regions, the occurrence and attractiveness of Singapore (area 1) account for a large proportion, which shows that Singapore is the logistics hub of Southeast Asia, and concentrates the main part of the Southeast Asia regional logistics exchange volume. Selang in Malaysia (area 3), Bangkok in Thailand (area 8), Ho Chi Minh City in Vietnam (area 17) and Jakarta in Indonesia (area 10) are the second largest. However, Myanmar's Yangon (area 19), Cambodia's Phnom Penh (area 20), and Indonesia's Jakarta (area 10) have less domestic freight exchanges. This result has important implications for regional economic development in Southeast Asia, the development of the logistics industry and the logistics services.

\section{Conflicts of Interest}

The author declares no conflicts of interest regarding the publication of this paper.

\section{References}

[1] Zhang, J. and Wang, K. (2010) Streamline Optimization Model with Logistics 
Supply-Demand Matching as the Goal. Journal of Southwest Jiaotong University, 45, 324-330.

[2] Silva, E.S. and Hassan, H. (2015) On the Use of Singular Spectrum Analysis for Forecasting U.S. Trade before, during and after the 2008 Recession. International Economics, 141, 34-49. https://doi.org/10.1016/j.inteco.2014.11.003

[3] Wang, D.J., Xia, G.E. and Ma, L. (2015) A Review of Research on Regional Logistics Demand Forecasting Methods. Oriental Enterprise Culture, 5, 181-184.

[4] Yu, B., Sun, A.G. and Chen, L.P. (2018) Forecast of Logistics Demand in Yunnan Province Based on Exponential Smoothing. Logistics Engineering and Management, 12, 38-40.

[5] Tian, L.N. (2011) Forecasting and Analysis of Interregional Logistics Demand Based on L-OD Method-Taking Luzhou City of Sichuan Province as an Example. Market Modernization, 8, 66-67. 